\section{A review of glaucoma treatment in Scotland 1994-2004}

\begin{abstract}
Objective This study evaluated the changing trends in glaucoma management in Scotland between 1994 and 2004.

Methods A retrospective analysis of national health statistics in Scotland from 1994 to 2004.

The Scottish morbidity record was used to collect information on all episodes of trabeculectomy. Data on number of prescriptions were gathered for individual drugs and also for groups of active ingredient. The population likely to have glaucoma (PLG) was calculated from estimates of prevalence in individuals aged 40 years and older, based on published epidemiological studies. The outcome measures were trabeculectomy rates, corrected for population likely to be at risk of glaucoma (PLG), and prescribing volume and cost for glaucoma medications.
\end{abstract}

Results Trabeculectomy rates have fallen by 67\% from 46 per 1000 PLG in 1994 to 15.4 per 1000 PLG in 2004. Over the same time period, the population likely to be at risk of glaucoma (PLG) increased by $16.6 \%$. The cost of prescribing has increased by $122 \%$ over 11 years compared with an increase in number of items per 1000 PLG by $27.5 \%$. In 1994, $\beta$-blockers accounted for $65.2 \%$ of prescribed drugs but by 2004 this had dropped to $33 \%$. Since their introduction, the prescribing of prostaglandin analogues has increased rapidly and in 2004 , they accounted for $39.4 \%$ of prescribed drugs.

Conclusion The increasing use of prostaglandin analogues has led to an increase in prescribing rates and a rapid increase in cost. At the same time, prescribing of $\beta$-blockers has declined and trabeculectomy rates have fallen.

Eye (2008) 22, 251-255; doi:10.1038/sj.eye.6702593; published online 22 September 2006
SM Macleod', R Clark², J Forrest², M Bain², $\mathrm{N}$ Bateman $^{3}$ and A Azuara-Blanco ${ }^{1}$

\section{Introduction}

The prevalence of glaucoma in the developed world has been calculated to be between 1.1 and $2.1 \%$, with increasing prevalence in the elderly. ${ }^{1,2}$ Glaucoma is usually a slowly progressive disease and the majority of people do not become blind. However, $12 \%$ of all blind registration in the United Kingdom is due to glaucoma and worldwide, there are approximately 4.5 million blind from this disease. ${ }^{3,4}$ As there are thought to be 67 million people affected with glaucoma worldwide, many more individuals may be visually handicapped by this condition. ${ }^{5}$

In the UK and in the Western world, the majority of cases of glaucoma are due to primary open-angle glaucoma. The current treatment for glaucoma consists of medical, laser (usually laser trabeculoplasty), and surgical (usually trabeculectomy). Topical $\beta$-blockers revolutionized the medical management of glaucoma in the late 1970s and for many years, they were the commonest topical treatment. In 1995, Dorzolamide (a topical carbonic anhydrase inhibitor (CAI)) was introduced in the UK, followed by Latanoprost (a prostaglandin analogue) and Brimonidine (an alpha 2 agonist) in 1997. These new treatments found rapid acceptance in the medical community. ${ }^{6}$ Since 1999 , a new topical CAI and two new prostaglandin analogues have been introduced, as well as combination treatments.

A previous report by Bateman et $a l^{6}$ showed that in the late 1990s, prescribing rates had increased after the introduction of new glaucoma treatments with a corresponding reduction in surgical rates. It was not known whether the apparent reduction of trabeculectomy rates would be temporary or would continue in the long term. In the current study, we assessed the cumulative data for an
${ }^{1}$ Department of Ophthalmology, Aberdeen Royal infirmary and University of Aberdeen, Aberdeen, Scotland

${ }^{2}$ Information Services Division, NHS National Services Scotland, Edinburgh, Scotland

${ }^{3}$ Scottish Poisons Information Bureau, Royal Infirmary of Edinburgh, Scotland, Scotland

Correspondence: A Azuara-Blanco, Department of Ophthalmology, Aberdeen Royal infirmary and University of Aberdeen, Foresterhill Road, Aberdeen AB25 2ZN, Scotland

Tel: +44 1224681818 ;

Fax: + 441224849156

E-mail: aazblanco@aol.com

Received: 31 January 2006 Accepted in revised form: 9 August 2006

Published online:

22 September 2006

Meeting presentation: Poster presentation at Glaucoma Society (UK \& EIRE) $26^{\text {th }}$ Annual Meeting, Friday 2nd December 2005 
11-year period, from 1994 to 2004, to establish if the trend for increasing medical treatment and decreasing surgical intervention had continued, which would confirm another revolution in the management of glaucoma.

\section{Methods}

The primary provider of health care in Scotland is the National Health Service (NHS) and health care is free to all residents.

The population likely to have glaucoma (PLG) was calculated from age-related estimates of prevalence in individuals aged 40 years and older, which were based on published epidemiological studies. ${ }^{7,8}$ Evaluating all available reports that gave age-specific estimates for prevalence of OAG, Quigley and Vitale ${ }^{7}$ proposed a model to estimate the prevalence of glaucoma for each age from 40 to 90 years in whites. Prevalence $=\left(1.59 \times 10^{-2}\right)-\left(1.14 \times 10^{-3}\right)$ $\times($ age -30$)+\left(3.39 \times 10^{-5}\right) \times($ age -30$){ }^{2}$

For each year studied, in each health board, the estimated prevalence for each age band was applied to census projections of the population within that age band (mid-year population estimate from the General Registrars Office). These were totalled to give the likely number of patients with glaucoma in each health board and in Scotland as a whole.

The NHS information and statistics division (ISD) uses the Scottish morbidity record (SMR) to collect information on activity in Scottish hospitals. Using the SMRs for acute hospital discharges (SMR01), all episodes were identified where a 'trabeculectomy' (OPCS4 code C60.1, which includes phacotrabeculectomy and non-penetrating trabeculectomy) had been performed between 1994 and 2004. Trabeculectomy rates per 1000 PLG were also calculated as were the number of argon laser trabeculoplasties.

Identification of and information on glaucoma drugs was obtained from the British National Formulary (BNF) section 11.6: Glaucoma. ${ }^{9}$ The Common Services Agency of the NHS in Scotland collects data on all NHS prescriptions, written by general practitioners in Scotland and dispensed by an NHS contractor. It does not gather hospital-prescribing data when the prescription is dispensed in the hospital. Data on number of prescriptions were gathered for individual drugs and also for groups of active ingredient according to their BNF subsection: miotics, sympathomimetics, topical $\beta$-blockers, CAIs, and prostaglandin analogues. Volume of prescribing (ie, number of prescribed items per 1000 PLG) and cost of prescribing in gross ingredient cost per 1000 PLG was calculated.

General ophthalmic activity (outpatient visits) data were also collected. Waiting times (median wait in days) for admission to ophthalmology wards following placement on waiting lists and waiting times for outpatient appointments following a referral by a general medical practitioner obtained from central data were also extracted. The numbers of cataract operations performed and staffing levels within Scotland were recorded.

Details of ophthalmology staff employed in the NHS in Scotland were collected by ISD via the Medical and Dental Census.

\section{Results}

The population of Scotland declined from 5102210 in 1994 to 5037824 in 2004, a drop of $1.3 \%$. However, the population likely to have glaucoma increased by $16.6 \%$ over the same period of time, from 37300 to 43500 . The average annual increase in PLG between 1994 and 1998 was $0.5 \%$. Since 1998, the average annual increase in PLG was around $1 \%$ with two larger increases of 7 and $2.9 \%$ from 1999 to 2000 and 2001 to 2002, respectively. A 1\% increase in PLG would result in an additional 435 patients likely to have glaucoma in Scotland in 2005 assuming a stable population.

In 2004, only 668 trabeculectomies were performed, a drop of $61 \%$ from 1714 in 1994 (Figures 1 and 2). The

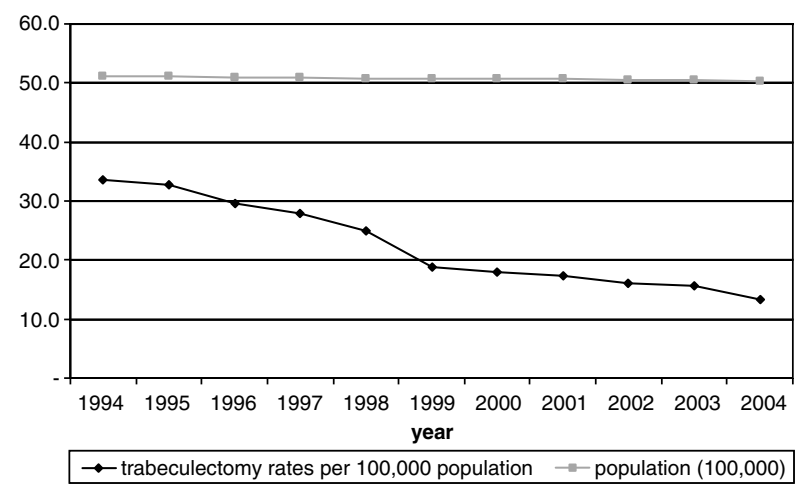

Figure 1 Population of Scotland in 100000's 1994-2004 and trabeculectomies per 100000 population, Scotland 1994-2004.

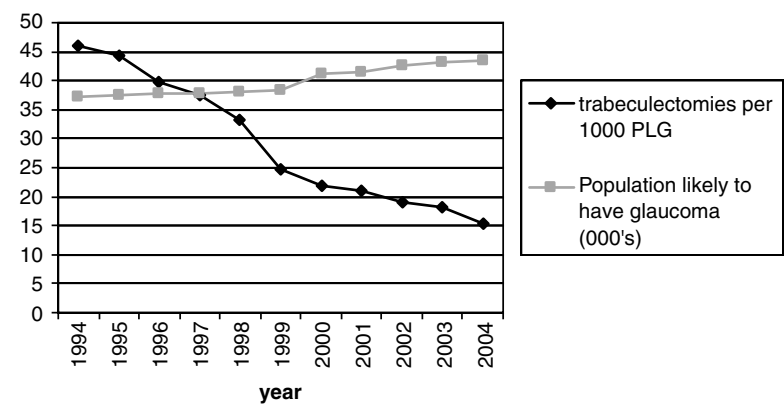

Figure 2 Population likely to have glaucoma (000's) and trabeculectomies per 1000 population likely to have glaucoma, Scotland 1994-2004. 
Table 1 Ingredient cost (£000) for BNF section 11.6 expressed per 1000 population likely to have glaucoma in Scotland, and items $(000$ 's) for BNF Section 11.6 expressed per 1000 population likely to have glaucoma in Scotland

\begin{tabular}{lcccccccccccc}
\hline & 1994 & 1995 & 1996 & 1997 & 1998 & 1999 & 2000 & 2001 & 2002 & 2003 & 2004 & $\%$ Change 1994-2004 \\
\hline Cost & 58 & 59 & 65 & 75 & 80 & 94 & 89 & 101 & 116 & 120 & 129 & 122 \\
Items & 8 & 8.1 & 8.5 & 8.9 & 9.4 & 9.9 & 9.2 & 9.6 & 9.7 & 9.9 & 10.2 & 27.5 \\
\hline
\end{tabular}



Figure 3 Cost (000's) per 1000 PLG and items (000's) per 1000 PLG, Scotland 1994-2004.

decrease in trabeculectomies performed contrasted with a general increase in ophthalmic activity. There was a $45 \%$ increase in cataract surgeries performed between 1994 and 2004, and a 19\% increase in whole-time equivalent medical staff over the same period. The number of argon laser trabeculoplasties performed each year was small, ranging from 33 per year in 1994 to 1 per year in 2001.

Prescribing costs increased by $122 \%$ over 11 years, from $£ 58000$ in 1994 to $£ 129000$ in 2004, compared with an increase in number of items prescribed of $27.5 \%$ over the same period (Table1 and Figure 3), with a maximum of 10159 items per 1000 population prescribed in 2004.

Prostaglandin analogues were the most commonly prescribed subsection in 2004 and accounted for $39.4 \%$ of the total items per 1000 PLG (Table 2 and Figure 4). Latanoprost comprised $92.5 \%$ of all prostaglandin analogues prescribed in 2004.

CAIs were the only other subsection to show an increase in prescribing. There were 1608 more items per 1000 PLG prescribed in 2004 compared to 1994. Topical CAIs accounted for $92 \%$ of all prescribed CAIs in 2004.

Prescribing of sympathomimetics and miotics decreased from 1994 to 2004. Brimonidine accounted for $88 \%$ of prescribed sympathomimetics in 2004. After its introduction in 1997, the prescribing of Brimonidine increased to a peak of 684 items per 1000 PLG in 2001 and has decreased annually since then. Prescribing of miotics and sympathomimetics together represented $7.9 \%$ of the total items per 1000 PLG in 2004.
Table 2 Percentage of items in subsections of BNF section 11.6 per 1000 population likely to have glaucoma, Scotland

\begin{tabular}{lcccc}
\hline & $\begin{array}{c}\text { Items per } \\
\text { 1000 PLG } \\
\text { in 1994 }\end{array}$ & $\begin{array}{c}\text { \% of } \\
\text { total in } \\
\text { 1994 }\end{array}$ & $\begin{array}{c}\text { Items per } \\
\text { 1000 PLG } \\
\text { in 2004 }\end{array}$ & $\begin{array}{c}\% \text { of } \\
\text { total in } \\
2004\end{array}$ \\
\hline Miotics & 1411.2 & 17.7 & 312 & 3.1 \\
Sympathomimetics & 1073.4 & 13.5 & 593 & 5.8 \\
$\beta$-blockers & 5182 & 65.2 & 3354 & 33 \\
CAIs & 285 & 3.6 & 1893 & 18.7 \\
$\begin{array}{l}\text { Prostaglandin } \\
\text { analogues }\end{array}$ & 0 & 0 & 4007 & 39.4 \\
Total items & 7951.6 & 100 & 10159 & 100 \\
\hline
\end{tabular}

Combination drops are classified according to the active ingredient that is not a $\beta$-blocker.

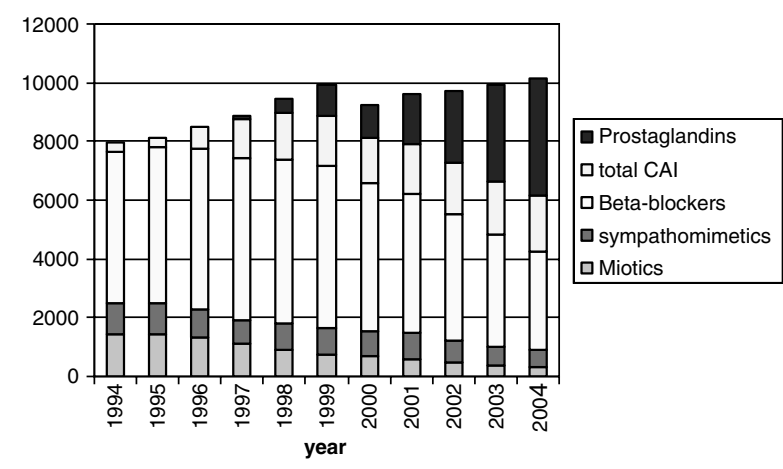

Figure 4 Prescribing rates per 1000 population likely to have glaucoma, Scotland 1994-2004.

$\beta$-blockers accounted for $33 \%$ of all prescribed items in 2004 with a total of 3354 items per 1000 PLG. There were two new combination drops introduced to the market after 1999, latanoprost with timolol (xalacom) and dorzolamide with timolol (cosopt). These two combination drugs accounted for $12 \%$ of all prescribed drugs in 2004. $\beta$-blockers used in combination with other drops accounted for an additional 1239 items per 1000 PLG in 2004.

\section{Discussion}

Glaucoma care has greatly changed during the recent past with the introduction of new medications and diagnostic technologies. In this national study of trends 
of glaucoma treatments during an 11-year period, a substantial change in the pattern and volume of prescriptions of anti-glaucoma medications has been noted. There was an overall increase in prescribing of $27.5 \%$ from 1994 to 2004 . The increase in the volume of prescribing is likely to be the result of changes in practice, although the population likely to have glaucoma has also increased by $16.6 \%$ over the same period.

$\beta$-blockers were introduced in the 1970s and for many years were the mainstay of treatment for glaucoma. Prescribing rates remained steady until 2000 when they started to drop. It would initially appear that prostaglandin analogues are now more frequently prescribed than $\beta$-blockers. This is partly due to the way that drugs are allocated to their BNF subsections, as combination drops are classified according to the active ingredient that is not a $\beta$-blocker. Prescribing of $\beta$-blockers alone or in any combination accounted for 4593 items per 1000 PLG in 2004, which represents $39.3 \%$ of the total medications prescribed and is slightly higher than the 4007 items per 1000 PLG represented by prostaglandin analogues. However, it is clear that the use of prostaglandin analogues has increased dramatically since they were introduced in 1997, with the market currently dominated by latanoprost. Although latanoprost is a more expensive topical treatment than $\beta$-blockers, it has fewer systemic side effects and it is slightly more efficacious than timolol. ${ }^{10}$ This improved efficacy is likely to result in fewer outpatient visits and fewer changes in treatment, so may lead to a cost saving that has not been quantified in this study.

These changes in prescribing have been accompanied by a large reduction in the number of operations for glaucoma in Scotland. The number of trabeculectomies per 100000 population was 61\% less in 2004 than 1994. This downward trend in Scotland has also been found in other countries including England, Australia, the USA, and France. ${ }^{11-14}$ The average cost of a day-case surgical procedure in the year ending 2004 was $£ 678$ (net). ${ }^{15}$ Six hundred and sixty-eight trabeculectomies were performed in Scotland in 2004. At an estimated cost of $£ 678$ per procedure, the total cost of surgery for the year would be $£ 452904$. Prescribing costs for 2004 were $£ 129000$ per 1000 PLG and as the estimated number of glaucoma patients in Scotland in 2004 was 43500, the total prescribing cost for the year was $£ 5611500$. The reduction in the number of trabeculectomies performed will offset to some extent the rise in the cost of prescribing, but in spite of this reduction the overall costs of direct glaucoma management has increased substantially.

Although the decrease in the trabeculectomy rate appears to be due to prescribing of new drugs, there may be several other possible explanations for why fewer filtering operations are being performed. It is possible that an increase in the use of antimetabolites in glaucoma surgery has improved the surgical outcome. There is no information available about the number of repeated trabeculectomies among the total number of surgeries. Although primary trabeculectomy has been reported to have success rates of up to $90 \%$, the current trend is to perform surgery if medical treatment fails. ${ }^{16-18}$ In the mid-1990s, primary trabeculectomy was proposed by some investigators and the decline in the number of trabeculectomies observed at the beginning of this study period may be due to a change in preferences. The observed drop in trabeculectomy rates may only be temporary as it is not yet clear if surgery is being delayed rather than prevented with the new drugs. Other possible factors such a reduction in the number of ophthalmologists, ophthalmic outpatient activity, and cataract surgery were not observed. An increase of other modalities of treatment such as laser trabeculoplasty was not seen.

In conclusion, we have shown changes in the management of glaucoma that indicate a major impact of new treatments on patient care. The soaring costs associated with prescribing of newer medication cannot be ignored, as the health-care budget is not unlimited. This extra expenditure may be at least partially compensated by a reduction in the number of operations. This information may impact upon the provision of glaucoma services.

\section{References}

1 Martinez GS, Campbell AJ, Reinken J, Allan BC. Prevalence of ocular disease in a population study of subjects 65 years old and older. Am J Ophthalmol 1982; 94: 181-189.

2 Klein BE, Klein E, Sponsel WE, Franke T, Cantor LB, Martone $\mathrm{J}$ et al. Prevalence of glaucoma: the Beaver Dam Eye Study. Ophthalmology 1992; 99: 1499-1504.

3 Resnikoff S, Pascolini D, Etya'ale D, Kocur I, Parajasegaram P, Pokrarel GP et al. Global data on visual impairment in the year 2002. Bull World Health Organ 2004; 82: 844-851.

4 Evans J, Rooney C, Ashwood F. Blindness and partial sight in England and Wales: April 1990-March 1991. Health Trends 1996; 28: 5-12.

5 Quigley HA. Number of people with glaucoma worldwide. Br J Ophthalmol 1996; 80: 389.

6 Bateman DN, Clark R, Azuara-Blanco A, Bain M, Forrest J. The impact of new drugs on management of glaucoma in Scotland: observational study. BMJ 2001; 323: 1401-1402.

7 Quigley HA, Vitale S. Models of open-angle glaucoma prevalence and incidence in the United States. Invest Ophthalmol Vis Sci 1997; 38: 83-91.

8 Tuck MW, Crick RP. The age distribution of primary open angle glaucoma. Ophthalmic Epidemiol 1998; 5: 173-183.

9 British National Formulary. British Medical Association and the Royal Pharmaceutical Society of Great Britain. London. Vol. 40, September 2000. 
10 Zhang WY, Po AL, Dua HS, Azuara-Blanco A. Metaanalysis of randomised controlled trials comparing latanoprost with timolol in the treatment of patients with open angle glaucoma or ocular hypertension. $\mathrm{Br} J$ Ophthalmol 2001; 85: 983-990.

11 Whittaker KW, Gillow JT, Cunliffe IA. Is the role of trabeculectomy in glaucoma management changing? Eye 2001; 15: 449-452.

12 Baudouin C, Rouland JF, Le Pen C. Changes in medical and surgical treatments of glaucoma between 1997 and 2000 in France. Eur J Ophthalmol 2003; 13(suppl 4): 53-60.

13 Walland MJ. Glaucomatreatment in Australia: changing patterns of therapy 1994-2003. Clin Exp Ophthalmol 2004; 32: 590-596.

14 Paikal D, Yu F, Coleman AL. Trends in glaucoma surgery incidence and reimbursement for physician services in the
Medicare population from 1995 to 1998. Ophthalmology 2002; 109: 1372-1376.

15 Scottish health service Costs 2003/2004. Section 5 Speciality group Costs - Day Cases: available at www.isdscotland.org/isd/files/Costs_Section5_2004.pdf.

16 Edmunds B, Thompson JR, Salmon JF, Wormald RP. The National Survey of Trabeculectomy. I. Sample and methods. Eye 1999; 13: 524-530.

17 Edmunds B, Thompson JR, Salmon JF, Wormald RP. The National Survey of Trabeculectomy. II. Variations in operative technique and outcome. Eye 2001; 15: 437-438.

18 Popovic V, Sjostrand J. Long-term outcome following trabeculectomy: I Retrospective analysis of intraocular pressure regulation and cataract formation. Acta ophthalmol (Copenhagen) 1991; 69: 299. 